\title{
The follies of ancestor worship
}

Can we identify fossil ancestors of species alive today? Dr Mark Siddall contends that this is impossible and that the use of stratigraphic data when assembling phylogenies is thus unsupportable.

\section{MARK SIDDALL}

In 1946, Princeton University celebrated its bicentennial with a series of conferences. One of these concerned the contributions of palaeontology to understanding phylogeny and evolution. Apparently, at its end, "members joked about returning to the Tercentenary celebration to see how much has been accomplished...and humbly expressed the hope...that some of the right questions will have been asked [there and then]" 1 .

Given the august setting in Nassau Hall, and the notable attendees such as Simpson, Mayr, Dobzhansky and Stebbins, I doubt the expression was entirely humble. Still, they were right to wonder about what questions would be asked thereafter.

We are now just 2 years past the half-way mark on that 100 year interval and it seems that the only question asked at the 1946 conference that remains interesting was posed by D. M. S. Watson. He wondered whether there might be "some primary measurable quantity with which change and all other measurement may be correlated"1. This anticipates the so-called molecular clock which keeps time about as well as a sundial in a November London fog. A point I will return to later.

\section{Fifty years on}

Most of what has transpired at the intersection of paleontology and phylogeny in the last 50 years was not even considered at the Princeton Conference because workers were still in the time "after Darwin [in which] the key to pattern became descent, guided by palaeontology. Hence the widespread view that fossils are the true guides to evolutionary relationships." $=$.

By the late 1970's this "Idol of the Academy" $\underline{3}$, what Pearson has called "ancestor hunting" but which Eldredge aptly named "ancestor worship" ${ }^{4}$, had been thoroughly debunked $\frac{5-7}{}$. The search for ancestor-descendant relationships instead of relationships of common ancestry was flawed. Ancestors can never be distinguished from sister taxa without placing a premium on negative evidence*.

This was hardly a new idea. Even Huxley had understood that "in dealing with fossils, [one] may mistake uncles and nephews for fathers and sons"

\section{The golden calf reforged}

Recently there has been a resurgence in the cult of reading ancestors in the fossil record. Stratophenetics ${ }^{2}$ begat stratocladistics $\underline{10}$. As expected from succession in phylogenetic methods, soon was born stratolikelihood 11 .

Some proponents of stratolikelihood methods carefully couch their arguments in terms of minimizing gaps in the fossil record as an optimality criterion, thus avoiding direct reference to ancestors. Others are more explicit about their desire for ancestors, and they are certainly apparent on 'stratolikeograms'는.

Measuring the fit between the placement of fossils in time and the structure of a tree was, at first, interesting. It provided "tests of the quality of specific fossil records" $\underline{12}$. There are various techniques for doing this $\stackrel{9-13}{ }$. If you can measure 
a fit, you can minimize it. And when you minimize it, it becomes an optimality criterion. But measuring and minimizing such a fit are very different. When you minimize it, you are no longer testing the quality of fossil records. You are testing the quality of the tree with the fossil record.

\section{The conundrum}

If the best tree based on character information intrinsic to the taxa disagrees with the extrinsic stratigraphic sequence of those taxa, so much the worse for the fossil record. Or is it the worse for the character phylogeny?

Some even suggest that it is a problem in the method of parsimony reconstruction, citing molecular analyses ${ }^{14}$. The problem with DNA is the limit of four states for all characters (A, C, G, \& T).

Even if one grants that likelihood ratios can allow incorporation of stratigraphic information and molecular data in simultaneous analysis, the fossils in question are almost inevitably devoid of the requisite A's, C's, G's and Ts. The way to save stratolikelihood would be to employ maximum likelihood for morphological data. It is not surprising then, that Wagner, for example, has tried 15 .

But Wagner cannot explain what 2.04 or 2.55 changes in number of metacarpals actually means 15 . Nor has he justified in biological terms the use of the mean number of changes across branches instead of the median, or the mode, or better yet, the natural logarithms of these numbers. Most importantly, for this to work the same stochastic model of change must apply equally for all morphological characters across all branches. Among other dubious things, this entails a well-oiled clock.

I remain unconvinced.

\section{Who are you going to believe?}

It is tempting to call incorporation of stratigraphic data in phylogeny a form of 'total evidence'. This already presupposes that stratigraphic placement is prima facie evidence of relationships. Specifically, that "the order in which species appear in the fossil record contains information about topology, because some topologies imply more missing time" $\underline{11}$.

But wait. Is it the order of appearance or is it the amount of missing time that is important?

These are not the same thing, notwithstanding Huelsenbeck and Rannala having conflated the two 11 . It is principally when fossil taxa are taken to be fathers (ancestors), not uncles, that order will minimize the amount of missing time.

\section{The logic of missing time}

Intuitively it might seem appealing to prefer a solution with less missing time (ignoring order). All things being equal, minimizing gaps in the fossil record is logical. But things are not all equal and this is not necessarily logical.

Fossil deposits, and our ability to recover them, are not stochastic things. The Signor-Lipps effect $\frac{16}{6}$ can cause rapid changes to appear gradual simply as a result of our sampling, particularly with respect to rare taxa. Preservation is not independent of whether there are hard-bits to be preserved, nor of the habitat preferences of the organisms.

Non-stochastic influences on preservation include the differences between sandy and rocky intertidal habitats, or forests and open plains. Orogenies, subductions and erosion all effect preservation, and these phenomena are hardly stochastically distributed in time or space. Any deviation from stochastic behaviour should cause us to expect gaps, not to minimize them

\section{Gaps in stochastic models}


More stunningly, even when the processes are allowed to vary stochastically in modelling analyses that permit realism, long gaps are expected!

Holland $\frac{17}{}$ included in his stochastic models of fossil preservation parameters for facies control 18,19 and parasequences (a water depth preference, a depth tolerance and cyclical changes in sea-level). Notwithstanding the underlying stochastic nature of these processes, what he found was that first and last preservations of taxa are non-randomly distributed in time. First occurrences cluster in strata from deeper water, last occurrences from shallow water.

Moreover, anomalously long gaps are the norm for taxa with narrow facies tolerance, or in periods of greater environmental variation. His models are born out in empirical data from bryozoans and trilobites. I expect they will continue to be. Specifically he noted that "clusters of occurrences of a taxon should be separated by anomalously long gaps" $\underline{17}$.

Rather than minimizing it, maybe we should be maximizing the amount of missing time.

Or perhaps we should just admit that the (extrinsically influenced) temporal distribution of fossils lacks the power to refute relationships based on character information intrinsic to the organisms.

Of course, this would send the sacred calf back to the smelter.

\section{Mark E. Siddal}

Museum of Zoology,University of Michigan,USA

\section{References}

1. Jepsen, G. L. \& Cooper, K. W. Genetics, Paleontology, and Evolution. (Princeton University Bicentennial Conference, Series 2, Conference 3, 1946).

2. Patterson, C. Significance of fossils in determining evolutionary relationships. Annu. Rev. Ecol. Syst. 12, 195-223 (1981).

3. Nelson, G. J. Ontogeny, phylogeny, paleontology and the biogenetic law. Syst. Zool. 27, 324-345 (1978).

4. Eldredge, N. Cladism and common sense. in Phylogenetic Analysis and Paleontology. 165-198 (Columbia University Press, 1979).

5. Farris, J. S. Phylogenetic classification of fossils with recent species. Syst. Zool. 25, 271-282 (1976).

6. Engelmann, G. F. \& Wiley, E. O. The place of ancestor-descendant relationships in phylogeny reconstruction. Syst. Zool. 26, 1-11 (1977).

7. Tattersall, I. \& Eldredge, N. Fact, theory, and fantasy in human paleontology. Amer. Sci. 65, 204-211 (1977).

8. Huxley, T. H. The anniversary address of the President. Q. J. Geol. Soc. London 26, XLII-LXIV (1870).

9. Gingerich, P. D. The stratophenetic approach to phylogeny reconstruction in vertebrate paleontology. in Phylogenetic Analysis and Paleontology. 41-77 (Columbia University Press, 1979).

10. Fisher, D. C. Stratigraphic parsimony. in MacClade. 124-129 (Sinauer Associates, Sunderland, MA, 1992).

11. Huelsenbeck, J. P. \& Rannala, B. Maximum likelihood estimation of phylogeny using stratigraphic data. Paleobiol. 23, 174-180 (1997).

12. Norell, M. A. \& Novacek, M. J. Congruence between superpositional and phylogenetic patterns: comparing cladistic patterns with fossil records. Cladistics 8, 319-337 (1992).

13. Siddall, M. E. Stratigraphic fit to phylogenies: A proposed solution. Cladistics 14, 201-208 (1998).

14. Huelsenbeck, J. P. \& Hillis, D. M. Success of phylogenetic methods in the four-taxon case. Syst. Biol. 42, 247-264 (1993).

15. Wagner, P. J. Predicting amounts of Stratigraphic debt and morphological change. J. Vert. Paleontol. 17, 83A (1997).

16. Signor, P. W. \& Lipps, J. H. Sampling bias, gradual extinction patterns, and catastrophes in the fossil record. Geol. Soc. Amer. Spec. Papers 
190, 291-296 (1982).

17. Holland, S. M. The stratigraphic distribution of fossils. Paleobiol. 21, 92-109 (1995).

18. Whittaker, R. H. Communities and Ecosystems. (MacMillan, New York, 1970)

19. Dodd, J. R. \& Stanton, R. J. Jr Paleoecology: concepts and applications (Wiley \& Sons, New York, 1990)

* The reason why ancestors cannot be distinguished from sister taxa is that a phylogenetic analysis which happens to include an ancestor can only be thought to do so by virtue of lack of any difference between it and the branch to which it connects; it lacks autapomorphies. If putative-ancestor X, has an autapomorphy, it is seen as distinct from the ancestral internode from which it derives. It cannot be an ancestor, since it does not reside on the internode. If it lacks autapomorphies, it could be postulated as an ancestor, but this would be due to the lack of an autapomorphy (that is lack of evidence). Thus there can be no positive evidence of ancestry. Lack of evidence can only allow it as a possibility. (Or an ad hoc postulate of reversal of the apomorphy before the next cladogenetic event). $\underline{\text { back }}$

Nature @ Macmillan Publishers Ltd 1998 Registered No. 785998 England. 